\title{
Patient safety: Prevention during care
}

\section{Vaidya A}

Assistant Professor, Department of Community Medicine, Kathmandu Medical College, Sinamangal, Nepal.

\begin{abstract}
A 65- year old woman is admitted to a hospital with fever. With a presumed diagnosis of pneumonia, she is treated with penicillin. On day 2, she develops a severe rash, felt to be caused by her infection. Service is very busy. No senior doctor is available. Penicillin is continued. Rash progresses. On day 4 she is confused, gets out of bed at night, floor is wet, and she slips and falls, fracturing hip. She dies on day 7. What happened?
\end{abstract}

If you look at the individual who made error, then you may say: junior doctor did not know what was causing the rash; senior doctor was not available; nurse was not there when patient got out of bed. However, the system also allowed errors to slip through: No good approach for dealing with very busy period; insufficient nurse staffing at night; operating room was too full and no surgeon available.

Broadly, this is an issue of Patient Safety. Rarely uttered, seldom heard, occasionally thought of, but always present. Patient Safety is a term used to describe the avoidance, prevention, and amelioration of adverse outcomes or injuries stemming from the processes of health care ${ }^{1}$. A subset of health care quality, Patient Safety includes errors, deviations and accidents that take place in during the course of treatment ${ }^{2}$. Some Patient Safety concerns in the global scenario include: unsafe injections (40\% syringes and needles reused nonsterilized)' unsafe blood (that leads to $5-15 \%$ of HIV infections in developing countries) and counterfeit drugs (that account for up to $30 \%$ of medicines consumed in developing countries) ${ }^{3}$.

The issue or rather interest in the issue is fairly new even in the international arena, and sometimes soaked with political motivations ${ }^{4}$. It started with the Harvard Medical Practice Study ${ }^{5}$ published in 1995 but the milestone publication that causes a lot of stir was the 'To Err Is Human' report ${ }^{6}$, published by Institute of Medicine, US in 1998. World Alliance for Patient Safety $^{7}$ was subsequently launched in 2004 and it immediately initiated the first Global Patient Safety Challenge in $2005^{8}$ : Clean Care is Safer Care, which focussed on Hand Hygiene in Health Care.
Patient Safety has been a grossly neglected topic in Nepal, almost a taboo. Patient Safety Culture that consists of the following five attributes ${ }^{9}$, are clearly absent or inadequate in most of our set-ups: a culture where all workers including front-line staff, physicians, and administrators accept responsibility for the safety of themselves, their co-workers, patients, and visitors; a culture that prioritises safety above financial and operational goals; a culture that encourages and rewards the identification, communication, and resolution of safety issues; a culture that provides for organisational learning from accidents; and finally, a culture that provides appropriate resources, structure, and accountability to maintain effective safety systems. How often do we pay heed to these issues during our practice- at hospitals, private clinics, health camps, and other places of patient care?

Nevertheless, Nepal has not been entirely quiet on Patient Safety issues. Medical error and negligence, or other safety issues such as anaesthesia and pharmacovigilance, which are important issues in Patient Safety, have been brought to attention in some scientific publications ${ }^{10-13}$. Even the newspapers sometimes raise safety issues like rational radiation use $^{14}$. But these 'buzz' are often masked by the 'bangs' of sensational headlines such as 'Hospital vandalized after patient's death' that usually ends with the expected '... the hospital management, however, denied negligence during the treatment' ${ }^{15}$.

Research in Patient Safety is an area that is of great importance and potential in Nepal. Some of the key questions ${ }^{16}$ that we need to answer through research are: what are the Patient Safety matters that are most relevant to our setting? Where are the gaps in Patient Safety in our healthcare? What are the factors responsible for them? What are the measures that can be implemented to reduce those gaps in Patient Safety? How we can those implement measures? How do we know that our interventions have worked and patient care is now safer than before?

In addition, there are two other dimensions in Patient Safety that needs attention. First one is regarding 
the consumers' rights to know about Patient Safety. Traditionally, this usually translates to obtaining of an informed consent prior to a surgery or a diagnostic procedure. But, this should also encompass security concerns like in case of fire or other disasters, to name a few. Thus, proper communication bridging between the providers and consumers is very essential. Second issue is safety of a patient before reaching a health. It must be acknowledged that a person becomes a patient not after entering a healthcare facility. So, pre-hospital Patient Safety - be it at home, or, on the way to the healthcare facility, is equally vital- particularly in the lack of proper ambulances or skilled attendees that transfer them to a hospital- a situation often marred by external factors such as traffic jams in the urban streets.

There must be efforts to bring into limelight this neglected issue of healthcare service. It may be added that work is underway to establish a critical mass in Nepal for research in Patient Safety with involvement of government and private institutes, concerned ministry, and international agencies.

\section{References}

1. Cooper JB, Gaba DM, Liang B, Woods D, Blum LN. National Patient Safety Foundation agenda for research and development in patient safety. Med Gen Med. 2000; 2(4): E38.

2. Cook RI, Render M, Woods DD. Gaps in the continuity of care and progress on patient safety. BMJ 2000; 320:791-4.

3. Eucomed Medical Technology [homepage on the Internet].Quarterlynewsletter-Issue64. [updated on 2008; cited on Jun 2010]. Available online at: www.eucomed.org/press/focus_on/ /media/ 770659A1C0F943DDBAC15D6E7D11FF52. ashx.

4. Clinton HR, Obama B. Making Patient Safety the Centerpiece of Medical Liability Reform. N Engl J Med. 2006; 354: 2205-8.

5. Harvard Medical Practice Study. Patients, doctors and lawyers: studies of medical injury, malpractice litigation, and patient compensation in New York. Boston: Harvard Medical Practice Study, 1990.Technical appendix 5.V.1.
6. Kohn LT, Corrigan JM, Donaldson MS, editors To err is human: building a safer health system. Washington, DC: National Academy Press; 1999.

7. World Health Organization [homepage on the Internet]. World Alliance for Patient Safety: forward programme. [updated on 2004; cited on Jun2010]. Available online at: www.who. int/patientsafety/en/brochure_final.pdf.

8. World Health Organization [homepage on the Internet]. First Global Patient Safety Challenge: Clean Care is Safer Care[updated on 2004; cited on Jun2010]. Available online at: http://www. who.int/gpsc/en/.

9. Agency for Healthcare Research and Quality. Making Health Care Safer: A Critical Analysis of Patient Safety Practices. Rockville MD: Agency for Healthcare Research and Quality; 2001.

10. Shrestha R. Medical negligence: An insight. Kathmandu University Medical Journal. 2008;24(6):533-4.

11. Hayes B. Medical errors- a hospital in Nepal searches for answers. Trop Doct. 2008;38:45-8.

12. Shrestha BM. Safety in anaesthesia - Nepali perspective. Kathmandu University Medical Journal. 2003;7(3):177- 81.

13. Khanal S, Gyawali S, Kanodia R, Rathor RS. Pharmacovigilance: Urgent need in mid-western region of Nepal. Kathmandu University Medical Journal (2009), Vol. 7, No. 4, Issue 28, 470.

14. Adhikari KP. Radiation safety in Nepal Strong measures called for. The Himalayan Times. Available online at: www.thehimalayantimes. com/fullNews.php?headline $=$ Radiation + safety + in + Nepal ++ Strong + measures + called + for \&N ewsID=247025 (accessed on 24 June 2010).

15. Nepalnews. Nepalgunj hospital vandalised after patient's death. Available online at: www.nepalnews.com/archive/2009/apr/apr14/ news10.php. (accessed on 24 June 2010)

16. Nieva V F, Sorra J. Safety Culture Assessment: A Tool for Improving Patient Safety in Healthcare Organizations. Qual Saf Health Care (2003): 12: ii17-ii23. 